\title{
Histidinemia en niños preescolares con trastornos de la comunicación oral
}

\author{
Denia Beltrán 1, Marcia de la Caridad López 1, Jiovanna Contreras 2, Daniel \\ Quintana 2, Lisset Fuentes 2, Orietta Hernández 2, Elsa Alonso 2, Ondina \\ Escalona 3 y Estela Morales 2. \\ 1 Hospital Pediátrico Pedro Borrás Astorga. Cuba \\ 2 Centro Nacional de Genética Médica. Cuba \\ 3 Hospital Pediátrico Universitario Juan Manuel Márquez. Cuba
}

\begin{abstract}
Resumen
Los trastornos de la comunicación oral en el niño son causa frecuente de asistencia a la consulta de Logopedia y Foniatría, donde el especialista debe realizar el examen clínico funcional en busca de posible etiología para imponer el tratamiento rehabilitador. Dentro de estos trastornos se encuentran los trastornos específicos del lenguaje y del habla, donde no se conoce la causa. La histidinemia se asocia frecuentemente con trastornos de la comunicación oral. Se realizó un estudio analítico de casos y controles. Se estudiaron 27 niños con trastornos de la comunicación (casos) y 102 controles. A todos se les determinó los niveles de histidina en suero mediante un método ultramicroanalítico. Presentaron niveles elevados de histidina el 29,6\% para los casos y en los controles solo el 1\%, determinándose que la diferencia en los niveles de histidina es significativa entre los niños con TEL y los controles mientras que los niños con dislalia no se diferencian significativamente ni de los controles, ni de los niños con TEL. Los resultados obtenidos muestran que la probabilidad de encontrar concentraciones de histidina elevadas en los niños con trastornos de la comunicación oral es más alta que en el grupo control.

Palabras clave: Histidina; Histidinemia; Trastorno específico del lenguaje.
\end{abstract}

\section{Histidinemia in preschoolers with communication disorders}

\begin{abstract}
Abstratc
Speech disorders are a common the most common causes of the Logopedia and Phoniatry consultation during childhood, point at which the specialist perform the clinic functional examination to find the etiology in order to begin an effective rehabilitation treatment. The specific language impairment and speech are among the speech disorders of unknown cause. Histidinemia is frequently associated with speech disorders. An analytical case-control study was developed in 27 cases with speech disorders and 102 controls. The concentration of histidine in serum of all children was determined by an ultramicroanalytic method. The histidine levels were elevated in the $29.6 \%$ of the case group and only in the $1.0 \%$ of the control group. The histidine level difference is more significant among between the language impairment group and the control group, while children with dyslalia did not differ significantly with the children with specific language impairment and the control groups. These results showed that histidine levels are likely to be more elevated in children with speech disorders than in the control group. Key words: Histidine; Histidinemia; Specific language impairment.
\end{abstract}

Correspondencia con los autores: jcontreras@cngen.sld.cu

Recibido 2 Mayo 2012. Revisado 13 Septiembre 2012. Aceptado 16 Octubre 2013. 


\section{Introducción}

El lenguaje infantil es uno de los indicadores de salud integral del niño. En los primeros años de vida hay una progresiva adquisición de funciones importantes como el control postural, la autonomía de desplazamiento, la comunicación y la interacción social. Esta evolución está estrechamente ligada con el proceso de maduración del sistema nervioso y a la organización emocional y mental. Requiere de una estructura genética adecuada y la satisfacción de los requerimientos básicos para el ser humano a nivel biológico y psicoafectivo (Conde, Conde, Bartolomé y Quiroz, 2009).

Las alteraciones del lenguaje oral constituyen un grupo de trastornos con alta prevalencia dentro de la población infantil. Los trastornos del lenguaje traen aparejados, además de las dificultades lingüísticas, déficit neuropsicológicos asociados que son tan importantes como los primeros a la hora de la rehabilitación. (Arboleda, et al, 2008, Conde, et al, 2009, Law, Garret, y Nyce, 2007). Los trastornos de la comunicación oral han sido estudiados ampliamente tanto desde el punto de vista lingüístico como desde la neuropsicología del desarrollo (Conde et al, 2009; Law et al, 2007; Valles, 2006; Quintana, et al, 2012). Las afecciones más frecuentes en la infancia son los retrasos del desarrollo del lenguaje, las dislalias y la tartamudez (Valles, 2006; Álvarez, et al, 2008).

De acuerdo a la clasificación internacional de enfermedades (CIE) los trastornos específicos del lenguaje y del habla están dentro de los trastornos del desarrollo psicológico y se dividen en (eCIE-10, 2009): Trastorno específico de la articulación del habla, trastorno expresivo del lenguaje, trastorno receptivo del lenguaje, afasia adquirida con epilepsia (Landau-Kleffner), otros trastornos del desarrollo del lenguaje y el habla y trastornos del desarrollo del lenguaje y el habla sin especificar.

El retraso del desarrollo del lenguaje puede ser secundario cuando se debe a varias causas, entre las que se encuentran: las lesiones estáticas del sistema nervioso central, alteraciones psíquicas, trastornos auditivos y el retraso mental que tienen peor pronóstico. Entre las causas de mejor pronóstico se relacionan, entre otras: pobre estimulación verbal, sobreprotección familiar, bilingüismo, enfermedades crónicas de la infancia, retardo en el uso de la masticación de sólidos en la dieta, uso prolongado de la televisión, enfermedades genéticas, etc. (Calderón y Salgado, 2004; Crespo y Narbona, 2006; López, 2004; Puyuelo, 2003; Quintana, et al, 2012). 
El trastorno específico del lenguaje (TEL) se caracteriza por un retardo en la adquisición de las habilidades lingüísticas de acuerdo a la edad cronológica, la mayoría de los autores coincide en que este diagnóstico se realiza por exclusión, es decir, todo desarrollo enlentecido o retrasado que no pueda ser puesto en relación con déficit sensorial, motor, cognitivo, con trastornos psicopatológicos ni con disfunciones cerebrales evidentes. Por lo que se llama también Retraso específico del lenguaje o disfasia de desarrollo por algunos autores (López, 2004). Hay poco consenso sobre la etiología del retraso o trastorno de lenguaje primario pero varios estudios sugieren correlaciones con factores de riesgo múltiples como: otitis media crónica, factores genéticos, nivel socioeconómico, dificultades en el embarazo y dificultades motoras orales (Calderón y Salgado, 2004; Puyuelo, 2003; Quintana et al, 2012).

En las últimas décadas se han llevado a cabo importantes progresos a la hora de comprender la etiología de los trastornos primarios o específicos del desarrollo del lenguaje, y en la actualidad se admite claramente que las causas son predominantemente neurobiológicas y en la que los genes desempeñan un papel sustancial. También, desde un punto de vista neuropsicológico, las investigaciones han arrojado datos sobre la existencia de limitaciones cognitivas en estos pacientes (Idiazábal y Saperas, 2008).

Son numerosos los trabajos que han puesto de manifiesto alteraciones en los estudios de neuroimagen, neurofisiológicos, genéticos y cognitivos, que demuestran básicamente la fisiopatología de esta entidad: anomalías estructurales y funcionales de la corteza cerebral, disfunción de estructuras subcorticales, predisposición genética, alteraciones cognitivas y factores ambientales. A pesar de lo que se plantea, mientras no se demuestre una causa evidente que provoque el retardo del desarrollo, se incluiría en esta entidad los pacientes sin causa conocida. Los trastornos del habla tales como la Dislalia y la Tartamudez son entidades muy frecuentes en la infancia temprana y se invocan numerosas teorías buscando la causa que las produce, se concluye en muchos casos de causa desconocida.

Las investigaciones genéticas del lenguaje dieron un giro sorprendente a raíz de la investigación de una familia inglesa (KE) en la que se daban alteraciones en la expresión del lenguaje en tres generaciones sucesivas. En este caso se demostró que todos los miembros afectados llevaban un cambio guanina por adenina (G/A) en el exón 14 del gen FOXP2 (forkhead P2). Desde entonces, este gen ha despertado un enorme interés por ser la primera evidencia de asociación de una mutación con un trastorno del lenguaje. Es conocido que el gen 
FOXP2 no es el gen del lenguaje; sino que es un gen que regula la expresión de otros muchos genes durante el período de desarrollo embrionario. De este gen se conoce que se expresa en áreas cerebrales relacionadas con el lenguaje (Nussbaum, Innes y Willard, 2008, Fisher y Scharff, 2009).

Las dificultades en las habilidades lingüísticas del niño son motivo de consulta frecuente en los servicios de Logopedia y Foniatría y en los de Genética Médica. En unas ocasiones puede ser el único problema, en otras es un síntoma dentro de un contexto más amplio: como se observa en la aparición de estos trastornos en los Errores Innatos del Metabolismo (EIM), que son un grupo de enfermedades genéticas determinadas por el bloqueo de un paso metabólico (Nussbaum, et al, 2008). La causa del bloqueo es la mutación de genes responsables del funcionamiento de dicho paso metabólico, ya sea porque el producto génico, que puede ser una enzima o una coenzima, esté cualitativamente o cuantitativamente afectado. El patrón de herencia es, en la gran mayoría de los casos, autosómico recesivo y en contadas situaciones es ligado al cromosoma X (Nussbaum, et al, 2008; Fisher y Scharff, 2009; Montoya, 2006; Stromswold, 2006).

La histidinemia es un EIM que consiste en la elevación de la concentración en sangre, orina y en líquido cefalorraquídeo del aminoácido Histidina (Stromswold, 2006; Virmani y Widhalm, 1993) así como la ausencia del ácido urocánico en los tejidos superficiales de la piel para la variante clásica (OMIM, 2006, Levy, Taylor y Mcinnes, 2001). Constituye uno de los EIM más frecuente en la edad infantil, con una incidencia de 1:15.000 y un patrón de herencia autosómica recesiva que cursa en muchas ocasiones con trastornos en el desarrollo del lenguaje. Es considerada como uno de los desórdenes más comunes del metabolismo de los aminoácidos, debido a la deficiencia de la enzima histidina amonio-liasa (HAL, OMIN), también conocida como histidasa, responsable de la desaminación no oxidativa de la histidina para formar el ácido trans-urocánico. Algunos autores señalan que la Histidinemia se asocia a trastornos del lenguaje, sin embargo no existe un consenso general al respecto. En tal sentido hay quien plantea que los niveles de histidina aumentados no se relacionan a síntoma alguno y que se trata de una condición benigna que se comporta de forma asintomática. (OMIM, 2006, Levy et al, 2001, Quintana, et al, 2012). Ante esta disyuntiva es importante profundizar sobre la relación de los niveles elevados de histidina y la aparición de los trastornos de la comunicación oral (López, 2004). 
Teniendo en cuenta que las causas genéticas provocan en gran medida trastornos del lenguaje y que el diagnóstico oportuno de los mismos, así como su tratamiento rehabilitador precoz, permiten la incorporación adecuada del niño a la sociedad y la prevención de discapacidades, resulta evidente la motivación para realizar el presente estudio sobre los niveles séricos de histidina en niños con trastornos de la comunicación oral.

\section{Método}

Se realizó un estudio observacional y analítico de casos y controles, con la finalidad de identificar el comportamiento de los niveles de histidina en suero en niños con y sin trastornos de la comunicación oral seleccionados, constituyendo el universo para los controles de 131 niños sin trastornos de la comunicación oral, que asistieron al laboratorio clínico de los Hospitales Pediátricos Universitarios "Pedro Borrás Astorga” y "Juan Manuel Márquez”; y para los casos fue de 2799 niños con trastornos del lenguaje que asistieron a la consulta de Logopedia y Foniatría del Hospital "Pedro Borrás", en el período comprendido entre Septiembre 2009Octubre 2011.

\section{Consideraciones éticas}

Se realizó previamente el proceso de obtención del consentimiento informado a los padres o tutores de los niños, obteniéndose el consentimiento informado por escrito de todos para participar en la investigación. Se han cumpliendo los principios éticos para las investigaciones médicas en seres humanos establecidos en la Declaración de Helsinki (JAMA, 2000).

\section{Criterios de inclusión:}

1.- Voluntariedad expresada mediante firma de consentimiento informado del padre o tutor del paciente.

2.- Para los controles: niños sin trastornos en la comunicación oral de edades comprendidas entre dos y siete años.

3.- Para los casos: niños de edades comprendidas entre los dos y seis años con los siguientes trastornos de la comunicación oral: TEL, retraso del lenguaje secundario a retraso mental de causa desconocida, dislalia propiamente dicha y tartamudez. 


\section{Criterios de exclusión:}

1. No aceptación de voluntariedad expresada de consentimiento informado del padre o tutor del paciente.

2. Niños mayores de ocho años y pacientes con otras afecciones logofoniátricas tales como: retraso secundario del desarrollo del lenguaje a otras entidades, tartaleo, disartria y dislalias funcionales simples, múltiples y orgánicas.

\section{Examen logofoniátrico:}

Todos los niños fueron evaluados en la consulta de Logopedia y Foniatría, se les realizó un examen logofoniátrico para constatar si presentaban o no trastornos de la comunicación oral y para caracterizar clínicamente los que tuvieran. Para la caracterización clínica de los niños con trastornos de la comunicación oral se realizó examen a través de la confección de la historia clínica logofoniátrica, para llegar a un diagnóstico logofoniátrico. A todos los niños incluidos en el estudio se les aplicó una encuesta, diseñada para la recolección de los datos (Anexo 1).

\section{Procedimiento}

A todos los niños participantes en el estudio se les realizó una extracción de $2 \mathrm{~mL}$ de sangre venosa para la cuantificación de histidina en suero mediante una micro técnica fluorimétrica empleando el Sistema Ultramicroanalítico (SUMA) (Contreras, et al, 2010).

Los pacientes que presentaron niveles elevados de histidina (punto de corte: $3,45 \mathrm{mg} / \mathrm{dL}$ ó 222,52 $\mu \mathrm{M})$, se les solicitó y recogió una muestra de sudor para realizar la cromatografía de capa delgada (TLC, por sus siglas en Inglés) para el ácido urocánico para descartar una histidinemia clásica (EIM, causa genética) (Contreras, Alonso, Escalona y Quintana, 2011).

La muestra del estudio quedó conformada por 102 niños control y 27 niños con trastornos del lenguaje, de acuerdo a los criterios de inclusión y exclusión ya descritos.

\section{Resultados}

La validación de los datos se realizó, de acuerdo a la distribución de los datos y la homogeneidad de varianza, aplicándose las pruebas estadísticas relevantes en cada caso (ANOVA, Prueba Scheffé) para una probabilidad del $95 \%$. 
En los pacientes estudiados predominó el sexo masculino y el grupo de edad de 2 años y 11 meses (Tabla 1). Observamos que la mayor frecuencia de niños con alteraciones del lenguaje pertenecen al primer y cuarto grupo de edades ( 24 a 35 y 60 a 71 meses, respectivamente). En la figura 1 se observa un predominio del sexo masculino y el color blanco de la piel en los niños estudiados. El sexo masculino aportó el 62,0 \% (80/129) y el sexo femenino el 37,9 \% (49/129). En el sexo masculino el 53,7 \% (43/80) correspondió a los niños con color blanco de la piel, el $11,3 \%(9 / 80)$ a los de piel mestiza y el 12,5\% (10/80) a los de piel negra. En el sexo femenino el 53,1 \% (26/49) correspondió al color blanco de la piel, el 20,4 \% (10/49) al color de la piel mestiza y el 8,2 \% (4/49) al color negro de la piel.

Tabla 1: Distribución de la muestra del estudio según la edad y el sexo.

\begin{tabular}{|c|c|c|c|c|}
\hline \multirow{2}{*}{$\begin{array}{l}\text { Edad } \\
\text { (Meses) }\end{array}$} & \multicolumn{2}{|c|}{ Sexo } & \multirow[t]{2}{*}{ Total } & \multirow[t]{2}{*}{$\%$} \\
\hline & Masculino & Femenino & & \\
\hline 24 a 35 & 23 & 19 & 42 & 32,6 \\
\hline 36 a 47 & 22 & 10 & 32 & 24,8 \\
\hline 48 a 59 & 13 & 2 & 15 & 11,6 \\
\hline 60 a 71 & 22 & 18 & 40 & 31,0 \\
\hline Total & 80 & 49 & 129 & 100 \\
\hline
\end{tabular}

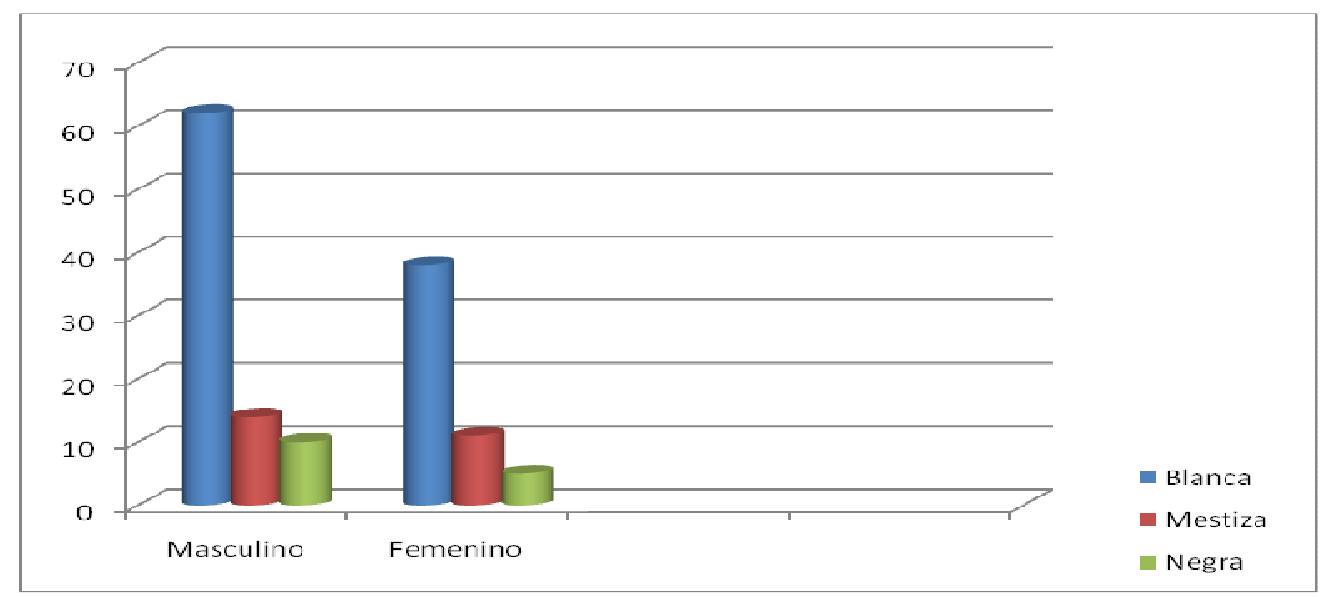

Figura 1: Distribución de la muestra del estudio según sexo y color de la piel. 
En la tabla 2 se reporta la distribución de los pacientes con trastornos de la comunicación oral según la edad, donde podemos observar que fue más frecuente el Trastorno específico del lenguaje (TEL) con un 55,6\% (15/27), en cambio el Trastorno del habla (Dislalia) solo aportó 44,4 \% (12/27), así mismo el grupo etario que más afectación tuvo fue el de edades comprendidas entre 36 a 47 meses con un $29,6 \%(8 / 27)$.

Tabla 2: Distribución de los pacientes según el trastorno de la comunicación oral y edad

\begin{tabular}{ccccc}
\hline $\begin{array}{c}\text { Edad } \\
\text { (Meses) }\end{array}$ & TEL & Dislalia & Total & $\mathbf{( \% )}$ \\
\hline 24 a 35 & 5 & 2 & 7 & 25,9 \\
36 a 47 & 5 & 3 & 8 & 29,6 \\
48 a 59 & 3 & 4 & 7 & 25,9 \\
60 a 71 & 2 & 3 & 5 & 11,1 \\
\hline Total & 15 & 12 & 27 & - \\
$(\%)$ & 55,6 & 44,4 & 100 & 100 \\
\hline
\end{tabular}

En la tabla 3 y figura 2 se reportan los niveles séricos de Histidina obtenidos para los casos y controles, de edades comprendidas entre 2 y 6 años. Hubo diferencias significativas en las concentraciones de Histidina para la media entre los grupos $(\mathrm{p}=0,000)$, encontrándose niveles elevados en el grupo correspondiente a los casos. Presentaron niveles elevados el 29,6 \% de los casos (8/27) y niveles normales en el 70,4 \% (19/27). Solo el 1\% (1/102) presentaron niveles elevados en el grupo control.

Tabla 3. Niveles de Histidina en suero para los grupos estudiados: controles y casos.

\begin{tabular}{cccc}
\hline & Controles & Dislalia & TEL \\
\hline $\mathrm{N}$ & 102 & 12 & 15 \\
Sexo & F: $40 \mathrm{M} ; 62$ & F: 5 y M: 7 & F: 4 y M: 11 \\
& & Histidina(mg/dL) & \\
Media \pm DE & $2,27 \pm 0,63$ & $3,11 \pm 1,19$ & $3,61 \pm 1,22$ \\
Mín-Máx & $0,90-4,06$ & $1,54-6,40$ & $1,86-5,80$ \\
IC 95 \% & 2,$15 ; 2,40$ & 2,$36 ; 3,87$ & 2,$92 ; 4,29$ \\
& & & \\
\hline
\end{tabular}




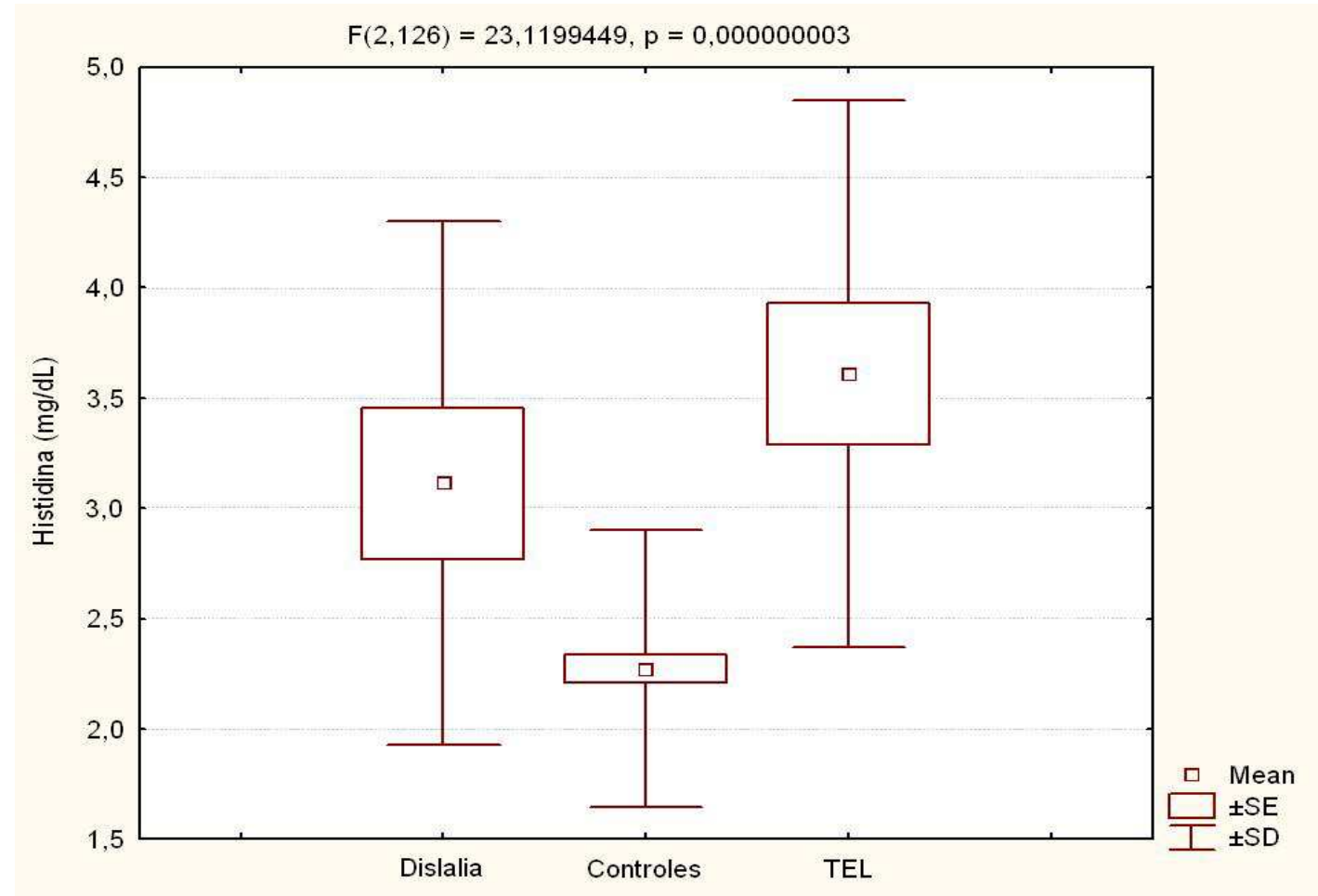

Figura 2. Niveles séricos de histidina para los casos (dislalia y TEL) y los controles.

De los 15 casos estudiados con TEL, en 5 se encontraron niveles de Histidina por encima de $3,45 \mathrm{mg} / \mathrm{dL}$, para un 33,3\% (5/15), a los pacientes que se le detectaron valores elevados se les realizó la cromatografía de capa delgada para el ácido urocánico en sudor, siguiendo en cada caso el algoritmo para el diagnóstico de la histidinemia (Anexo 2). En el 100\% de los casos el área de lenguaje afectada fue la expresiva. Además, en el 70,4 \% de los casos (19/27) presentaron niveles normales de histidina.

De los 27 casos estudiados (TEL y Dislalia) el 29,6 \% (8/27) presentaron niveles elevados de Histidina, a los que siguiendo el algoritmo de estudio se les realizó la TLC de ácido urocánico en sudor y se obtuvo la presencia del metabolito, confirmándose el diagnóstico de histidinemia atípica (Contreras et al, 2011, Quintana, et al, 2012), no encontrándose la variante clásica.

Utilizando la prueba ANOVA se obtuvo diferencias significativas $(p=, 002)$ entre los casos (dislalia y TEL) y los controles. Para realizar la comparación múltiple y analizar en que pares está la diferencia utilizamos la prueba de Scheffé (Tabla 4), determinándose que la diferencia en los niveles de histidina es significativa entre los niños con TEL y los controles 
$(p=, 001)$, mientras que los niños con dislalia no se diferencian significativamente ni de los controles, ni de los niños con TEL.

Tabla 4. Resultados de la Prueba Scheffé para los casos y controles en relación a los niveles de histidina.

\begin{tabular}{cccc}
\hline & Dislalia & TEL & Controles \\
& $\mathrm{M}=3,11$ & $\mathrm{M}=3,61$ & $\mathrm{M}=2,28$ \\
\hline Dislalia & & .420354 & .053454 \\
TEL & .420354 & & .000398 \\
Controles & .053454 & .000398 &
\end{tabular}

Scheffé Test; Variable His (mg/dL) Controles (Casos vs Control). Significación $\mathrm{p}<.05$

\section{Discusión}

El manejo del paciente portador de afecciones logofoniátricas consiste en la detección, evaluación y diagnóstico que se le realice al paciente para ubicarlo en el nivel de desarrollo alcanzado. Uno de los aspectos más importantes es la detección precoz de los trastornos, que permitirá actuar de forma rápida, minimizando y/o eliminando las posibles repercusiones psicológicas, pedagógicas y sociales en el individuo (Álvarez, et al, 2008).

Aunque los valores de la prevalencia para las dificultades del habla y el lenguaje en su totalidad varían entre un $1 \%$ y un $15 \%$, se piensa que como promedio, alrededor del $6 \%$ de los niños pueden tener dificultades del habla y el lenguaje, de los cuales una proporción significativa tiene retrasos primarios del habla y el lenguaje (Conde, et al, 2009; Arboleda, et al, 2008; Puyuelo, 2003). En esta investigación la casuística coincide con los parámetros de prevalencia internacional.

Los resultados obtenidos en relación a la distribución de la muestra del estudio según la edad y el sexo coinciden con otros estudios realizados (Álvarez, et al, 2008; López, 2004; Calderón, 2004; Salgado, 2004, Quintana, et al, 2012) donde se plantea que los trastornos de la comunicación oral son más frecuentes en el sexo masculino y en las primeras etapas de desarrollo del lenguaje infantil, donde el niño se encuentra en plena etapa de aprendizaje de la lengua materna. El primer año de vida resulta crucial en el aprendizaje del lenguaje. A lo largo de este periodo, el bebé afina, gracias a su experiencia creciente, toda una serie de capacidades 
de base que le permiten interactuar intencionalmente a un nivel pre verbal con el adulto (Calderón, 2004; Monfort y Juárez, 1987; Montoya, 2006; Narbona y Chevrie, 2000).

Consideramos que lo que sucede con el primer grupo de edad se debería a la mejor asistencia en la Atención Primaria de Salud en las consultas de Puericultura en edades tempranas, con relación al otro grupo en orden de frecuencia. Esto puede deberse a la preocupación de los padres ante un niño que comienza la edad escolar y no tiene un lenguaje adecuado, lo que presupone una insuficiente la labor de pesquisa y promoción de salud con relación a los trastornos de la comunicación en la atención pediátrica.

No se encontró en la literatura revisada referencias sobre la relación del color de la piel con los trastornos del lenguaje.

La menor cantidad de niños con dislalia en el estudio pudiera deberse a que en esas edades tempranas los niños se encuentran en la fase de desarrollo fonológico, por lo que no es frecuente encontrar esa afección, no obstante se puede diagnosticar esta entidad con un buen examen clínico y funcional de la comunicación oral por un especialista de Logopedia y Foniatría. Resultados similares se reportan en la literatura consultada, donde se plantea que los trastornos de la comunicación oral son más frecuentes en las primeras etapas de desarrollo del lenguaje infantil en que se encuentra en plena etapa de aprendizaje de la lengua materna, donde intervienen una serie de factores, como, por ejemplo el medio en que se desenvuelve (Álvarez, et al, 2008; Calderón, 2004; Crespo, 2006; López, 2004; Montoya, 2006; Puyuelo, 2003, Salgado, 2004).

Está descrito que durante los 15 primeros meses de la vida del bebé tiene lugar una importante evolución de la actividad vocal y perceptiva. A nivel productivo, el fenómeno es comparable con lo que ocurre a nivel receptivo, el niño pasa del estado de balbuceo indiferenciado a la emisión exclusiva de fonemas pertenecientes a la lengua materna. Hacia los 6 u 8 meses de edad, el niño empieza a tener un cierto control de la fonación y de manera bastante clara, también a nivel de la prosodia (Calderón, 2004; Monfort y Juárez, 1987; Nicolás, 2001).

Estas dos entidades logofoniátricas (TEL y dislalia) son frecuentes en las consultas médicas, incluso constituyen motivo de consulta en otras especialidades. Estas entidades, como se explicó con anterioridad, no se conoce la causa que las produce; por lo que las variables que pudieran incidir en la aparición de estos trastornos, fueron controladas en el estudio, nos referimos a la ausencia de factores neurobiológicos y socio ambientales en estos pacientes, tales 
como la calidad de estimulación del lenguaje recibida, el manejo educativo, audición, desarrollo psicomotor, etc.

Las diferencias obtenidas en los niveles de Histidina para los casos y controles en este estudio se corresponden con los reportes de la literatura, donde se plantea que es más frecuente encontrar niveles de Histidina elevados en niños con trastornos de la comunicación oral que en aquellos que no lo presentan (Céspedes, Santisteban, Rojas y Ortiz, 2002; Levy, Taylor y Mcinnes, 2001; Nussbaum, et al, 2008, OMIM, 2006; Quintana, et al, 2012; Robaina, et al, 2010; Samoano et al, 2012).

Investigaciones realizadas sobre la histidinemia en Cuba evidencia relación entre este EIM y los trastornos en el desarrollo del lenguaje, (Contreras et al, 2010, Robaina, et al, 2010; Samoano, et al, 2012) encontrando que la probabilidad de hallar niveles altos de histidina en un individuo con trastornos del lenguaje aislado, de causa desconocida, fue cerca de treinta veces superior (Odd Ratio= 29,75, IC95\%: 7,04; 125,8) a la observada en el grupo control, demostrándose que existe mayor probabilidad de encontrar niveles elevados en el grupo de niños con trastornos de la comunicación oral que en los controles (Robaina, et al, 2010).

El 70,4 \% de los casos (19/27) presentaron niveles normales de histidina, reportes similares aparecen en la literatura, pues muchos autores coinciden en que la histidinemia es un defecto benigno que puede cursar de forma asintomática, (Lam, et al, 1996, OMIM, 2006, Levy, et al, 2001) confirmado también en los resultados obtenidos en el grupo control.

\section{Referencias}

Arboleda, R., Lopera, V., Hincapié, H., Giraldo, P., Pineda, D., Lopera, F., et al., (2008). Trastorno específico del desarrollo del lenguaje: problema selectivo o generalizado de la cognición. Revista de Neurología, 44, 596-600.

Álvarez, L., Fernández, C., Ferrer, S., López, M., Capó, A., y Regal, C. (2008). Logopedia y Foniatría. La Habana: Ciencias Médicas.

Conde, P., Conde, M., Bartolomé, M., y Quiróz, P. (2009). Perfiles neuropsicológicos asociados a los problemas del lenguaje oral infantil. Revista de Neurología, 48, 32-40.

Crespo, N., y Narbona, J. (2006). Subtipos de Trastorno Específico del Desarrollo del Lenguaje: Perfiles clínicos de una muestra hispanoparlante. Revista de Neurología, 43, 193-200. 
Contreras, J., Hernández, O., Alonso, E., Robaina, Z., y Gutiérrez, E. (2008). Validación de un micro método fluorimétrico para la cuantificación de 1-Histidina en sangre periférica. Revista Cubana de Genética Comunitaria, 2, 37-45.

Contreras, J., Alonso, E., Escalona, O., y Quintana, D. (2011). Detección del ácido urocánico en sudor mediante el empleo de la cromatografía en capa delgada. Revista Cubana de Genética Comunitaria, 5, 23-34.

Céspedes, C., Santisteban, I., Rojas, E., y Ortiz, D. (2002). Detección de Fenilcetonuria y otros errores congénitos del metabolismo en centros de educación especial de Costa Rica.

Fisher, S.E., y Scharff, C. (2009). FOXP2 as a molecular window into speech and language. Trends in Genetics, 25, 166-77.

Idiazábal-Aletxa, M.A., y Saperas-Rodríguez, M. (2008). Procesamiento auditivo en el trastorno específico del lenguaje. Revista de Neurología, 46, 91-95.

Law, J., Garret, Z., y Nyce, C. (2007). Intervenciones de terapia del habla y el lenguaje para niños con retraso o trastorno primario del habla y el lenguaje. Oxford: John Wiley \& Sons.

Levy, H., Taylor, R., Mcinnes, R., y Scriver, C. (2001). The metabolic bases of inherited disease. New York: McGraw-Hill.

Lam, W., Cleary, M., Wraith, J., y Walter, J. (1996). Histidinaemia: a benign metabolic disorder. Archieves of Disease in Childhood, 74, 343-346.

Monfort, M., y Juárez, A. (1987). El niño que habla. El lenguaje oral en preescolar. Madrid: CEPE.

Nussbaum, R., McInnes, R., y Willard, H. (2008). Genetics in medicine. Philadelphia: Thompson \& Thompson.

Nicolás, J. (2001). Alteraciones del habla en la infancia. Aspectos clínicos. La Habana: Ciencias Médicas.

Narbona, J., y Chevrie-Muller, C. (2000) El lenguaje del niño: Desarrollo normal, evaluación y trastornos. Barcelona: Masson.

Puyuelo, M. (2003). Manual de Desarrollo y Alteraciones del lenguaje. Barcelona: Massón.

Quintana, D., Lantigua, P., López, M., Contreras, J., Vila, D., et al (2012). Delineación clínicogenética de pacientes con histidinemia. Actas de Memorias Convención Internacional de Salud Pública. Cuba. 
Quintana, D., Aguilar, L., Lantigua, P., Tasé, D., Calixto, Y., Contreras, J.. et al. (2013). Características electroencefalográficas de niños con trastornos en el desarrollo del lenguaje con y sin histidinemia. Revista Cubana de Neurología y Neurocirugía, 3, 117121.

Robaina, Z., Bosch, D., Contreras, J., Moreno, J., Texidor, L., López, M., et al. (2010) Histidinemia y trastornos del lenguaje en una muestra de la población cubana. Revista Cubana de Genética Comunitaria, 4, 29-31.

Stromswold, K. (2006) Why aren't identical twins linguistically identical? Genetic, prenatal and postnatal factors. Cognition, 101, 333-84.

Somoano, R. M., Ramírez, Y., Díaz, M., y Rodríguez, D. (2012). Histidinemia atípica y desarrollo cognitivo. Revista Cubana Endocrinológica, 23, 157-165.

Valles, G, (2006). El análisis polisistémico aplicado al diagnóstico del trastorno articulatorio. http://www.espaciologopédico.com/artículos Último acceso 30 Junio 2007.

Virmani, K., y Widhalm, R (1993). Histidinemia, a biochemical variant or a disease? Journal of the American College of Nutrition, 12, 115-124.

World Health Organization. eCIE-10 (2009) Clasificación Internacional de las enfermedades. Capítulo V. Trastornos mentales y del comportamiento. Disponible en: http://cie10.org/.

World Medical Association Declaration of Helsinki: Ethical principles for medical research involving human subjects. 
Anexo 1: Encuesta para la recolección de datos según historia clínica logofoniátrica.

Número de orden:

Nombre del estudiado:

Edad:

Sexo: Raza:

Dirección:

Examen de la comunicación oral:

\section{Nivel I. Lenguaje}

Lenguaje Expresivo:

( ) Ausente.

( ) Uso de Jerga (con fines comunicativos, sin fines comunicativos)

( ) Vocabulario adecuado y preciso para su edad.

( ) Combinación de palabras y frases en oraciones.

( ) Presencia de elementos dislálicos

( ) Trastornos de fluencia.

Lenguaje Receptivo:

( ) Oye bien.

( ) Entiende lo que se le dice y sus respuestas son adecuadas.

( ) Repetición de los sonidos que escucha.

( ) Órdenes sencillas.

( ) Órdenes complejas.

Lenguaje Extraverbal:

( ) Uso de gestos y señas.

( ) Expresa estados emocionales

( ) Comprende gestos y señas.

\section{Nivel II. Habla:}

Articulación general:

Inteligible 
Ininteligible

Fluencia

Articulación aislada:

Por niveles articulatorios:

Nivel I: P, B (V), M, F

Nivel II: T, D, N, S, L (s y c), R ( 1, 2, 3, 4, 5)

Nivel III: CH, Y (LL), $\tilde{\mathrm{N}}$

Nivel IV: K, G, J

\section{Nivel III. Voz:}

Examen de los atributos de la voz: Tono, timbre, intensidad, resonancia, entonación.

Tiempo de fonación.

Laringoscopia indirecta.

Examen físico general y de los órganos fonoarticulatorios.

Diagnóstico logofoniátrico: 
Anexo 2: Algoritmo para el diagnóstico Genético y Bioquímico para la histidinemia.

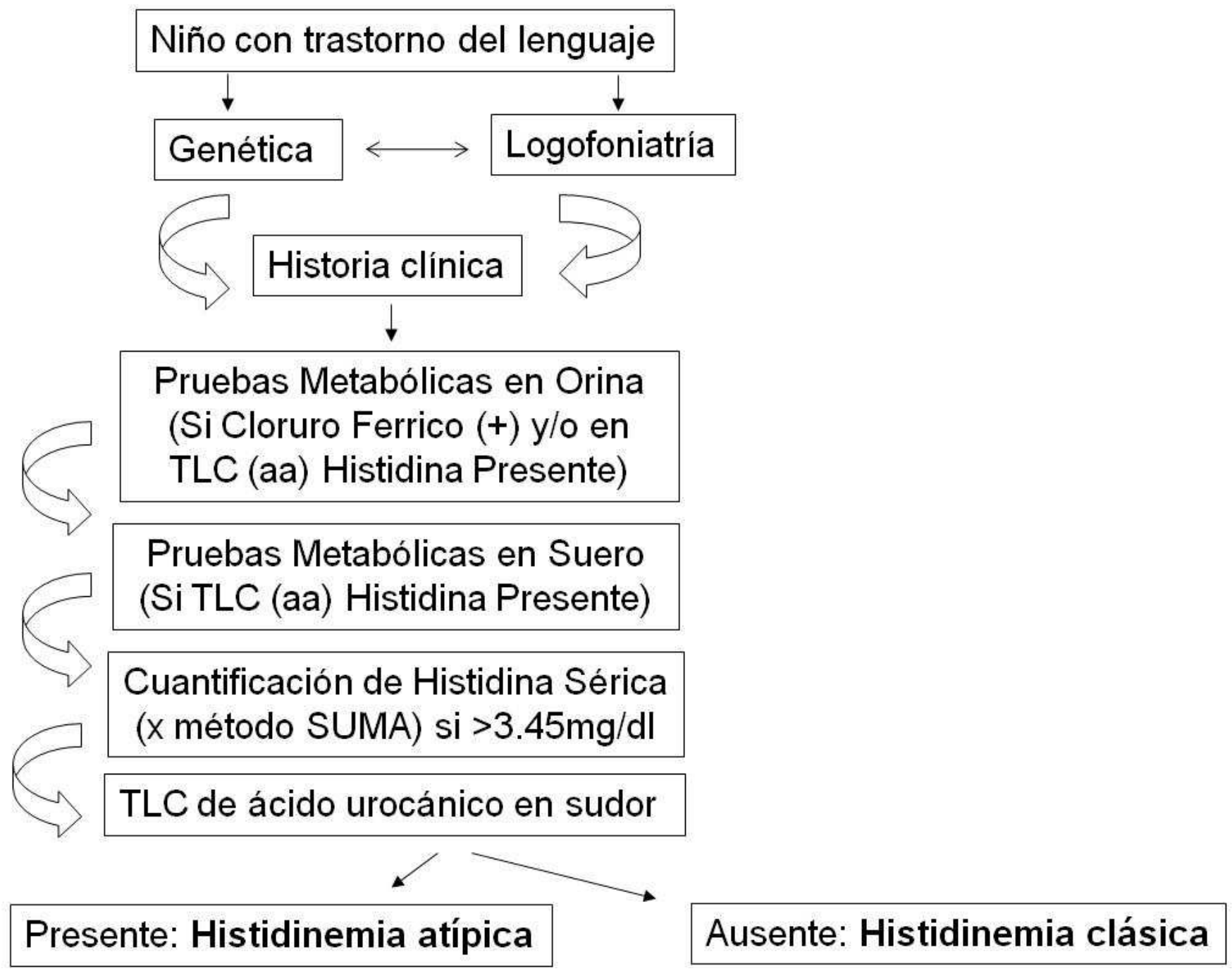

